\title{
Experience of arthroscopic surgery in tophaceous gout: indications, results and complications
}

\author{
W. Tan, J. Chen, R. Ran, W. Zheng, N. Oshmianska \\ Chengdu Rheumatism Hospital, Chengdu city, Sichuan Province, China
}

\begin{abstract}
Background Gout, lasting 5 years or more, and high uncontrollable levels of uric acid in blood lead to the formation of tophi - gouty stones containing the UA crystals surrounded with connective tissue. As the result of tophi formation in the joint area patients felt extreme discomfort and quite often completely lose ability to work. Objectives To define indications for tophaceous gout surgery in the Chengdu Rheumatism Hospital, evaluate surgical results and complications, as well as the effectiveness of a new surgery equipment. Materials and methods The indications and results of tophaceous gout surgery were investigated in 63 male gout patients of Chengdu Rheumatism hospital in 2019-2020. A retrospective analysis was carried out on the basis of medical records for all patients who were prescribed with urate lowering therapy and underwent arthroscopic intervention or complex surgical intervention combining arthroscopic shaving with open tophectomy procedure. Results The most common lesion site was foot joints: toes (49.41 \%), ankle (39.68 \%) and knee $(34.92 \%)$, with restricted mobility in the mentioned joints. Among common complaints were inability to perform daily routines due to enlarged joints (inability to wear shoes), joints' dysfunction and pain. Younger patients (aged 20-44) had significantly higher levels of uric acid in serum before treatment. In most cases, indications for surgery for this group of patients were pain and discomfort in joints, inability to perform daily work. After accessing pain levels, $38.46 \%$ of younger patients reported pain leveled 6 or higher on VAS score, which was more often, compared to patients aged 45-55 (26.92\%) and older than $55(10.0 \%)$. After surgery and following urate lowering therapy all patients noted functional improvement and reduction of pain. Decrease in serum urate levels were reported in $96.83 \%$ of patients. Conclusion The results of surgical treatment for functional impairment of the joint (inability to perform daily work due to restricted range of motions) and massive joint transformation (inability to wear shoes/clothes) in gout patients are positive, with all patients reporting functional improvement and reduction of pain, and the risk of complications is low. In addition to urate lowering therapy we cautiously recommend performing arthroscopic shaving even in younger gout patients consistent with aforementioned indications.

Keywords: gout, hyperuricemia, tophi, arthroscopic shaving
\end{abstract}

\section{INTRODUCTION}

Gout is an inflammatory disease caused by tissue deposits of monosodium urate monohydrate crystals secondary to hyperuricemia $[1,2]$. The prevalence of gout is $1.14 \%$ of the general population in China and $1-4 \%$ in other countries [2]. Recurrent acute arthritis may result in the development of articular syndrome (especially in the first metatarsophalangeal joint with the auricle), stones and gout nephropathy [3].

Chronic polyarthritis develops in gout patients after several attacks of the acute arthritis and is characterized by longer attacks and other joints involvement in inflammation (so-called joints of the second line), and later development of tophi $[4,15]$. Deformation of joints leads to restricted mobility, contractures, atrophy of muscles but rarely ankylosis. Patients felt extreme discomfort and quite often completely lose ability to work. Articular syndrome continues to develop against the background of chronic gouty arthritis. The most unfavorable outcome is the development of "gout status" which is characterized by continuous exacerbation of arthritis caused by massive infiltration of uric acid (UA) crystals in the surrounding tissues with formation of chronic inflammatory reaction [5]. As a rule, lasting disease of 5 years or more and high uncontrollable levels of UA lead to the formation of tophithe gouty stones containing UA crystals surrounded with connecting tissue $[6,7]$. They might be localized on auricles, elbows, elbow joints, on feet, fingers, extensor surface of forearms, hips, shins, on a forehead, in the cartilaginous partition of a nose. Tophi often are accompanied by thinning of skin in the joint area, formation of fistulas from which contents may seep spontaneously in the form of pastelike white substance. Approximately $12-35 \%$ of the gout patients develop tophi $[3,7,15]$.

Due to the rarity of surgical treatment for gout, surgery is limited to isolated case reports and case series [8]. The most common surgical techniques are arthroscopic shaver and open tophectomy. The reported outcomes were generally positive with restoration of function while the most common adverse outcome was delayed wound healing. This justifies the need of systematic research with the deep statistical analysis of indications, results and complications for tophaceous gout surgery.

\section{MATERIALS AND METHODS}

Medical records of 63 male patients with gout who underwent joints surgery were included in the study. All patients were admitted to Chengdu Rheumatism
Hospital in 2019-2020, prescribed with urate lowering therapy and underwent arthroscopic intervention or complex surgical approach combining arthroscopic 
shaving with open tophectomy procedure. The study was performed in accordance with the principles of the Declaration of Helsinki and approved by the Ethics Committee of Chengdu Rheumatism Hospital. All participants provided written informed consents.

Data collection. In all patients anthropometrical parameters were measured, including waist circumference, body height and weight, body mass index (BMI). In addition, blood pressure at systolic and diastolic phases, blood levels of triglycerides, fasting serum glucose, and creatinine were measured. Serum UA was measured on the first day and after the end of treatment by standard ELISA method. C-reactive protein (CRP) and other standard laboratory tests were performed on turbidimetry analyzer Mindray BC-5300.
Affected joints were assessed by X-ray and in some cases magnetic resonance imaging, size of lesions was measured using X-ray images.

Statistical analysis Baseline characteristics of participants were evaluated by descriptive statistics and results were presented in the form of mean \pm standard deviation. Comparisons in the means of continuous variables with a normal distribution were performed by using Student's t-test. Comparisons in medians of continuous variables with a skewed distribution were performed by using a Wilcoxon rank-sum test. All reported probability values (P-values) were based on two-sided tests and $P$ value $<0.05$ was considered statistically significant. Statistical analysis was conducted using IBM IPSS statistics software (version 23, IBM Co., Armonk, NY, USA).

\section{RESULTS}

A total of 63 patients with gout were included in this study, all patients of male gender. The mean age of gout patients was $47.24 \pm 11.81$ years, with CRP values varying from 0.35 to 193.04 (mean $19.365 \pm 35.51$ ) and the mean serum UA before treatment was $503.35 \pm 124.35 \mu \mathrm{mol} / \mathrm{L}$. The most common lesion site was foot joints: toes (49.41\%), ankle (39.68\%) and knee (34.92\%), with restricted mobility in the mentioned joints. Among common complaints were inability to perform daily routines due to enlarged joints (inability to wear shoes), joints' dysfunction and pain. Other general characteristics of study patients are described in Table 1.

Sepsis control was indication for surgery only in $4.76 \%$ of patients. All of them were of older age, with a long history of gout and in considerable amount of joints pain (scored 6 in VAS).

Younger patients (aged 20-44) had significantly higher levels of UA in serum before treatment. In most cases, indications for surgery for this group of patients were pain and discomfort in joints, inability to perform daily work. After accessing pain levels, $38.46 \%$ of younger patients reported pain leveled 6 or higher on
VAS score, which was more often, compared to patients aged 45-55 (26.92\%) and older than 55 (10.0\%).

It is important to note, that despite gout being considered the disease of older generation, there was a reasonable amount of younger patients in our hospital with disabling deformations of joints and tophi site 6 $\mathrm{cm}$ or more in diameter (Fig. 1), who benefited from the surgical treatment.

Table 1

General characteristics of gout patients, who underwent surgery

\begin{tabular}{|c|c|}
\hline Factor & Value $(\mathrm{M} \pm \mathrm{m})$ \\
\hline Age, years & $47.24 \pm 11.81$ \\
\hline $\begin{array}{c}\text { Serum UA before treatment, } \\
\mu \mathrm{mol} / \mathrm{L}\end{array}$ & $503.35 \pm 124.35$ \\
\hline Serum UA after treatment, $\mu \mathrm{mol} / \mathrm{L}$ & $306.49 \pm 89.37$ \\
\hline ESR & $20.098 \pm 19.98$ \\
\hline CRP & $19.365 \pm 35.51$ \\
\hline Lesion localization & $\%$ of pts \\
\hline Toes (including 1st joint $)$ & 46.03 \\
\hline Ankle & 39.68 \\
\hline Knee & 34.92 \\
\hline Other & 46.03 \\
\hline
\end{tabular}

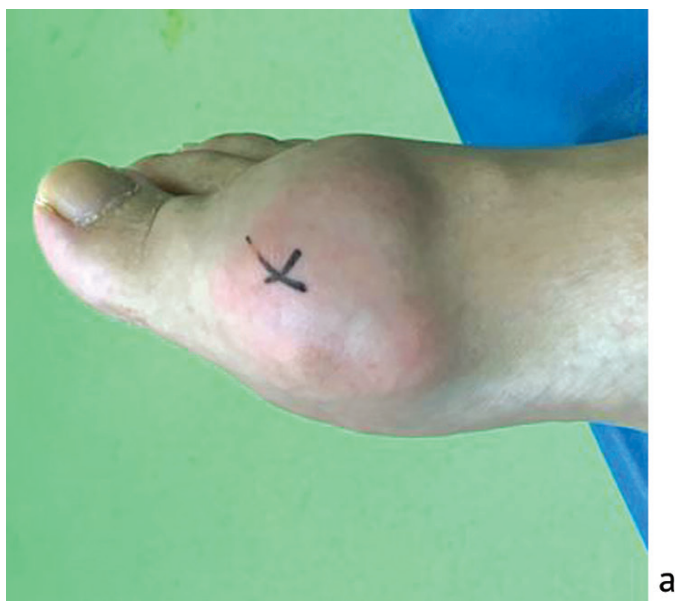

Fig. 1 Massive deforming tophus of toe joint in 31 years old patient: $\boldsymbol{a}$ before surgery, large tophus sized $5 \times 4$ sm; $\boldsymbol{b} 24$ hours after surgery, wound healing without complications 
Most patients aged 45-55 had slightly elevated levels of CRP, with $50 \%$ of those patients having CRP $>5 \mathrm{mg} / \mathrm{L}$. Indications for surgery in this age group included big deforming tophi lesions, often in the region of ankle and elbow, which was reported significantly more often compared to younger patients (see Table 2). Hyperuricemia in this group was less pronounced, with mean serum UA of $461.44 \pm 118.57 \mu \mathrm{mol} / \mathrm{L}$.

Majority of patients underwent surgery in one or two sessions. Patients younger than 45 were less likely to have surgery carried out on two or more joints (61.54\% compared to $72.73 \%$ in patients older than 55). Extracted mass size ranged from 1.0 to $7.0 \mathrm{~cm}$ in diameter, mean size almost the same for all age groups.

Two patients reported elevation of serum UA after surgery intervention up to $410.1 \mu \mathrm{mol} / \mathrm{L}$ (349.3 before surgery) and $445.6 \mu \mathrm{mol} / \mathrm{L}$ (313.6 before surgery). One of them was 20 y.o., another one 53 y.o., both had a relatively small (to $2 \mathrm{~cm}$ in diameter) lesion of the first metatarsophalangeal joint, in both cases removed by arthroscopic shaving. Most likely serum UA elevation was not related to the performed surgery, but long-term follow up needed to exclude the possibility of postsurgical complications.

Wound healing was 1.5 weeks on average; in older patients with multiple lesions, diabetes or other concomitant disorders it took up to 3 weeks.

Majority of patients aged over $55(60 \%)$ reported hypertension, but only one had diabetes. Indications for surgery in this age group included multiple tophi lesions, often in the region of wrist and fingers (see Fig. 2). Functional impairment and drastically restricted range of motions in the hand joints was more of a concern to those patients than pain.

After surgery and following urate lowering therapy all patients noted functional improvement and reduction of pain. Decrease in serum urate levels were reported in $96.83 \%$ of patients. The longer follow-up period is needed to fully evaluate functional outcome (6-month follow-up examinations were scheduled for all patients).

Table 2

Localization of tophi and number of joints demanded surgical intervention

\begin{tabular}{|l|c|c|c|}
\hline & Group 1 $(<45), \mathrm{n}=26$ & Group 2 (45-55), $\mathrm{n}=26$ & Group 3 $(>55), \mathrm{n}=11$ \\
\hline One joint involved & 38.46 & 30.77 & 27.27 \\
\hline Two or more joints involved & 61.54 & 69.23 & 27.73 \\
\hline \multicolumn{2}{|l|}{ Lesion localization } & 42.31 & 54.54 \\
\hline- Toe joints/ first toe & 57.69 & 46.15 & 18.18 \\
\hline - Ankle & 26.92 & 26.92 & 9.09 \\
\hline- Knee & 50.00 & 34.62 & 18.18 \\
\hline- Elbow & 30.77 & 7.69 & 45.45 \\
\hline- Wrist & 7.69 & 30.77 & \\
\hline - Fingers & 23.08 & & \\
\hline
\end{tabular}
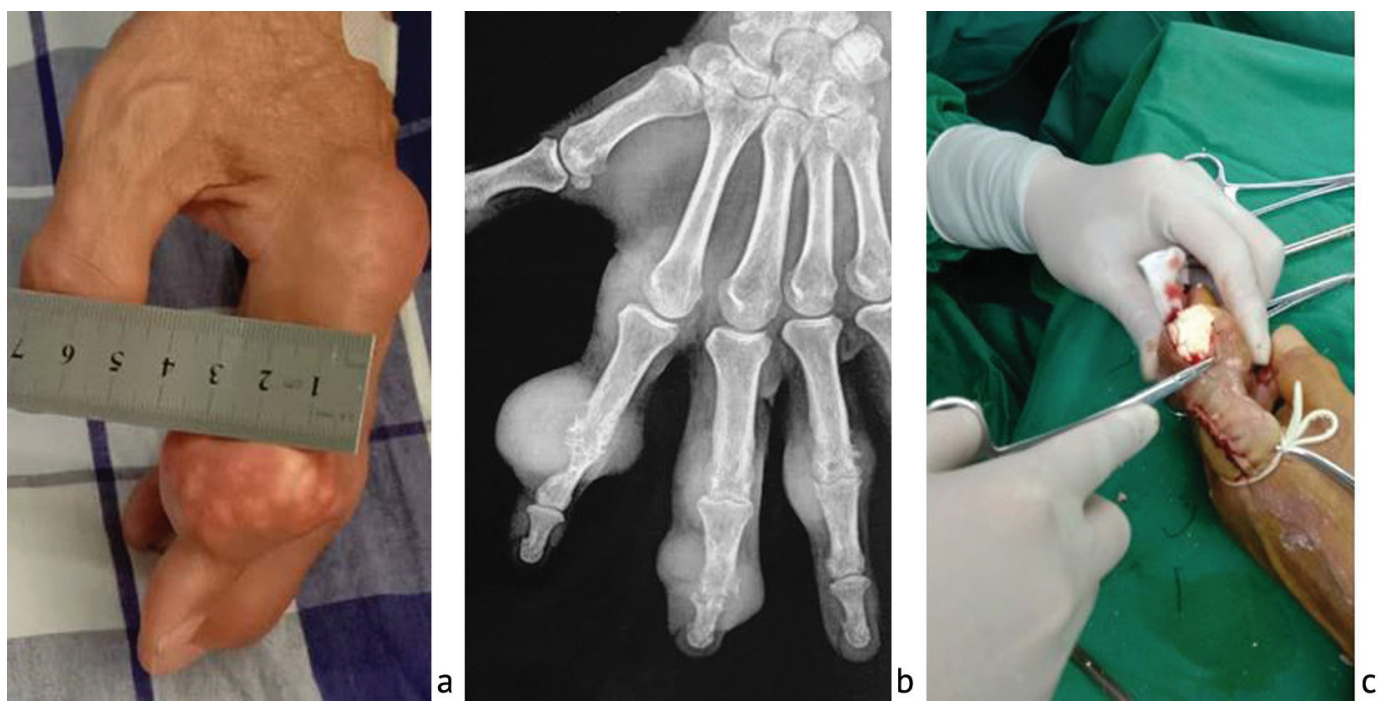

Fig. 2 Multiple tophi lesions of wrist and fingers in 70 years old patient: $\boldsymbol{a}$ before surgery; tophi restricting function and mobility of hand; $\boldsymbol{b}$ before surgery; X-ray demonstrates diffuse crystallization in almost every hand joint; $\boldsymbol{c}$ during surgery; large tophaceous masses are being extracted by open tophectomy

\section{DISCUSSION}

The lack of controlled clinical studies in the published literature makes it harder to determine when, or if, surgery needs to be recommended to a specific patient.

In our hospital 2 most common indications for surgery were functional impairment of the joint (inability to perform daily work due to restricted range of motions) and massive joint transformation (inability to wear shoes/clothes). $26.98 \%$ of all patients underwent surgery for pain control, majority of them being younger than 45 years old. Important to note, that pain control wasn't the sole complain, it always accompanied the functional impairment. Sepsis 
control and local infection was indication for surgery only in $4.76 \%$ of patients.

There is no clear "metabolic indication" for the surgical removal of tophi as the mechanical removal of tophus does not appreciably decrease total body urate burden [9]. Our patients, in addition to surgery, all were prescribed with urate lowering therapy and $96.83 \%$ reported reduced hyperuricemia at the end of treatment.

Surgery can potentially restore function faster compared to medical therapy and prevent complications in some individuals with persistent tophi [10]. However, in considering surgical intervention for tophaceous gout, it is often challenging to balance these potential advantages against the risks associated with surgery [11].

Based on our experience, arthroscopic shaving is affective technique to access smaller tophi and softer lesions, in patients of all ages (including younger gout patients with a functional impairment). For the excision of large tophi, complex surgical approach is needed, combining open tophectomy and aspiration of tophaceous masses.

In the published literature, the best reported surgical outcomes seem to be for patients who have failed, or are intolerant of medical treatment for tophaceous gout, but have not yet developed substantial loss of function, infection, or skin ulcerations [12]. Unfortunately, some of the same circumstances that lead to medical treatment failure may be associated with surgical treatment failure. These include poor adherence to therapeutic recommendations (such as post-operative physiotherapy), adherence with post-surgical medications, and necessary medical monitoring in the post-operative period $[13,14]$.

\section{CONCLUSION}

The results of surgical treatment for functional impairment of the joint (inability to perform daily work due to restricted range of motions) and massive joint transformation (inability to wear shoes/clothes) in gout patients are positive, with all patients reporting functional improvement and reduction of pain, and the risk of complications is low. In addition to urate lowering therapy, we cautiously recommend performing arthroscopic shaving even in younger gout patients consistent with aforementioned indications.

Conflict of interest statement None of the authors have any conflict of interest regarding this manuscript.

\section{REFERENCES}

1. Mandell B.F. Clinical manifestations of hyperuricemia and gout. Cleve Clin. J. Med., 2008, no. 75 Suppl 5, pp. S5-S8. DOI: 10.3949/ccjm.75.suppl 5.s5

2. Dehlin M., Jacobsson L., \& Roddy E. Global epidemiology of gout: Prevalence, incidence, treatment patterns and risk factors. at. Rev. Rheumatol., 2020, Vol. 16, no. 7, pp. 380-390.

3. McLean L., Becker M. Etiology and pathogenesis of gout. In: M.C. Hochberg, A.J. Silman, J.S. Smolen, M.E. Weinblatt, M.H. Weisman, eds. Rheumatology. Elsevier Ltd., Mosby, 2011, Section 14, No 187, pp. 1555.

4. Puig J.G., Martínez M.A. Hyperuricemia, gout and the metabolic syndrome. Curr. Opin. Rheumatol., 2008, vol. 20, no. 2, pp. 187-191. DOI: 10.1097/ BOR.0b013e3282f4b1ed

5. Khanna P.P., Nuki G., Bardin T., Tausche A.K., Forsythe A., Goren A., Vietri J., Khanna D. Tophi and frequent gout flares are associated with impairments to quality of life, productivity, and increased healthcare resource use: Results from a cross-sectional survey. Health Qual. Life Outcomes, 2012, vol. 10, pp. 117. DOI: 10.1186/1477-7525-10-117

6. McQueen F.M., Chhana A., Dalbeth N. Mechanisms of joint damage in gout: evidence from cellular and imaging studies. Nat. Rev. Rheumatol., 2012, vol. 8, no. 3, pp. 173-181. DOI: 10.1038/nrrheum.2011.207

7. Ragab G., Elshahaly M., Bardin T. Gout: An old disease in new perspective - a review. J. Adv. Res., 2017, vol. 8, no. 5, pp. 495-511. DOI: 10.1016/j. jare.2017.04.008

8. Kasper I.R., Juriga M.D., Giurini J.M., Shmerling R.H. Treatment of tophaceous gout: When Medication is not enough. Semin. Arthritis Rheum., 2016, vol. 45, no. 6, pp. 669-674. DOI: 10.1016/j.semarthrit.2016.01.005

9. Kumar S., Gow P. A survey of indications, results and complications of surgery for tophaceous gout. N. Z. Med. J., 2002, vol. 115, no. 1158, pp. U109.

10. Wang C.C., Lien S.B., Huang G.S., Pan R.Y., Shen H.C., Kuo C.L., Shen P.H., Lee C.H. Arthroscopic elimination of monosodium urate deposition of the first metatarsophalangeal joint reduces the recurrence of gout. Arthroscopy, 2009, vol. 25, no. 2, pp. 153-158. DOI: 10.1016/j.arthro.2008.09.002

11. Khanna D., Fitzgerald J.D., Khanna P.P., Bae S., Singh M.K., Neogi T., Pillinger M.H., Merill J., Lee S., Prakash S., Kaldas M., Gogia M., Perez-Ruiz F., Taylor W., Lioté F., Choi H., Singh J.A., Dalbeth N., Kaplan S., Niyyar V., Jones D., Yarows S.A., Roessler B., Kerr G., King C., Levy G., Furst D.E., Edwards N.L., Mandell B., Schumacher H.R., Robbins M., Wenger N., Terkeltaub R.; American College of Rheumatology. American College of Rheumatology guidelines for management of gout. Part 1: Systematic nonpharmacologic and pharmacologic therapeutic approaches to hyperuricemia. Arthritis Care Res. (Hoboken), 2012, vol. 64, no. 10, pp. 1431-1446. DOI: 10.1002/acr.21772

12. Edwards N.L. Treatment-failure gout: a moving target. Arthritis Rheum., 2008, vol. 58, no. 9, pp. 2587-2590. DOI: 10.1002/art.23803

13. Lee S.S., Chen M.C., Chou Y.H., Lin S.D., Lai C.S., Chen Y.C. Timing of intra-lesion shaving for surgical treatment of chronic tophus. J. Plast. Reconstr. Aesthet. Surg., 2013, vol. 66, no. 8, pp. 1131-1137. DOI: 10.1016/j.bjps.2013.03.041

14. Öztürk R., Atalay İ.B., Bulut E.K., Beltir G., Yılmaz S., Güngör B.Ş. Place of orthopedic surgery in gout. Eur. J. Rheumatol., 2019, vol. 6, no. 4, pp. 212215. DOI: 10.5152/eurjrheum.2019.19060

15. Atakhanova L.E., Tsurko V.V., Buleva I.M., Boiko I.N., Zheleznov S.P., Ivanova T.B. Podagra: Ot etiologii i patogeneza k diagnostike i ratsionalnoi farmakoterapii [Gout: From etiology and pathogenesis to diagnosis and rational pharmacotherapy]. Sovremennaia Revmatologiia, 2007, vol. 1, no. 1, pp. 13-18. (in Russian) DOI: 10.14412/1996-7012-2007-433

Received: 31.08 .2020

\section{Information about the authors:}

1. Wei Tan, M.D., Ph.D.,

Chengdu Rheumatism Hospital, Chengdu, China,

ORCID iD: https://orcid.org/0000-0002-8560-1870,

Email: tw18181420391@163.com

2. Jianchun Chen, M.D.,

Chengdu Rheumatism Hospital, Chengdu, China, ORCID iD: https://orcid.org/0000-0003-2538-2132, Email: cjc18030541834@163.com

3. Ran Ran, M.D.,

Chengdu Rheumatism Hospital, Chengdu, China, ORCID iD: https://orcid.org/0000-0002-9835-1188, Email: rr19181737867@163.com
4. Wuyan Zheng, M.D.,

Chengdu Rheumatism Hospital, Chengdu, China,

ORCID iD: https://orcid.org/0000-0002-5133-9472, Email: 1642637460@qq.com

5. Nataliia Oshmianska, M.D.,

Chengdu Rheumatism Hospital, Chengdu, China, ORCID iD: https://orcid.org/0000-0001-8027-5693, Email: 1283182076@qq.com 